\title{
Sistem Administrasi Pelayanan Surat Mahasiswa Berbasis Web Dan Mobile Android
}

\author{
Henny Alfianti ${ }^{*}$, Aris Haris Rismayana ${ }^{2}$ \\ 1, 2 Program Studi Teknik Informatika, Politeknik Tedc Bandung \\ 1,2J1. Politeknik - Pasantren KM. 2 Cibabat, Cimahi Utara, Kota Cimahi, 40513, Indonesia \\ E-mail: hennyalfianti@poltektedc.ac.id ${ }^{1}$, rismayana@ poltektedc.ac.id ${ }^{2}$
}

\section{Info Naskah:}

Naskah masuk: 14 Juni 2020

Direvisi: 27 Juli 2020

Diterima: 6 Agustus 2020

\begin{abstract}
Abstrak
Perguruan tinggi merupakan instansi pendidikan yang tidak lepas dari aktivitas pelayanan mahasiswa, khususnya pelayanan surat mahasiswa. Saat ini aktivitas pelayanan surat mahasiswa di Politeknik TEDC Bandung, masih menggunakan metode konvensional. Mahasiswa yang ingin membuat pengajuan surat tertentu, harus kerap kali mengisi data pada formulir kertas untuk membuat pengajuan surat. Permasalahan yang terjadi adalah data tidak terorganisir dengan baik, banyaknya kertas yang harus di cetak untuk formulir pelayanan berbagai macam surat dan juga petugas pelayanan masih harus memasukkan data pada formulir ke dalam surat yang di ajukan oleh mahasiswa secara manual. Berdasarkan masalah tersebut, perlu dibuat sistem administrasi pelayanan surat mahasiswa untuk mengelola berbagai pengajuan surat mahasiswa. Metode yang digunakan pada penelitian ini adalah waterfall. Perancangan database menggunakan MySQL dan bahasa pemrograman yang digunakan adalah PHP dan Java. Hasil penelitian ini adalah adanya sistem administrasi yang mampu mengelola data pengajuan surat mahasiswa, mulai dari pengajuan, surat diproses, hingga pemberian notifikasi kepada mahasiswa bahwa surat telah selesai diproses. Dari hasil pengujiannya, 82,8 \% responden setuju bahwa sistem mampu melakukan pengelolaan pengajuan surat mahasiswa.
\end{abstract}

\section{Keywords:}

student services;

web;

mobile.

\begin{abstract}
Universities are educational institutions that cannot be separated from student service activities, especially student letter services. Currently, student letter service activities at the TEDC Polytechnic Bandung are still using conventional methods. Students who wish to make certain letter submissions must often fill in data on paper forms to make letter submissions. The problems that occur are the data is not well organized, the large number of papers that must be printed for service forms of various kinds of letters and also service officers still have to enter data on the form into letters submitted by students manually. Based on this problem, it is necessary to create a student letter service administration system to manage various student letter submissions. The method used in this research is waterfall. The database design uses MySQL and the programming languages used are PHP and Java. The result of this research is that there is an administrative system that is able to manage student letter submission data, starting from submission, letters being processed, to giving notification to students that the letter has been processed. From the test results, $82.8 \%$ of respondents agreed that the system was able to manage student letters.
\end{abstract}




\section{Pendahuluan}

Perguruan tinggi sebagai instansi pendidikan tentunya membutuhkan sistem informasi yang digunakan untuk mengatur kegiatan akademik agar menjadi lebih cepat dan efektif, serta efisien dan akurat untuk meningkatkan standar mutu pendidikan [1]. Pelayanan pada perguruan tinggi terkait informasi yang dibutuhkan mahasiswa cukup mendapat sorotan. Mahasiswa memiliki kebutuhankebutuhan yang meliputi kebutuhan persuratan, kebutuhan nilai, kebutuhan sebuah informasi dan lain-lain dalam memenuhi pelaksanaan pada jenjang pendidikannya [2]. Terkait aspek pelayanan yang ada di perguruan tinggi, terdapat banyak pelayanan yang perlu ditingkatkan, diantaranya adalah sistem administrasi pelayanan surat mahasiswa [3]. Administrasi pelayanan surat menyurat merupakan salah satu titik pokok yang penting di dalam suatu instansi pendidikan.

Pemanfaatan TIK terutama penerapan penggunaan sistem informasi [4] pada bidang layanan administrasi akademik di perguruan tinggi saat ini menjadi suatu kebutuhan wajib agar dapat meningkatkan daya saing perguruan tinggi tersebut [5]. Politeknik TEDC Bandung merupakan salah satu perguruan tinggi yang sebagian besar pengolahan data dan kebutuhan informasi pada instansi ini sudah di tangani oleh sistem informasi, tetapi di beberapa bagian seperti bagian administrasi persuratan mahasiswa di akademik masih menggunakan sistem manual untuk melakukan pelayanan dan pembuatan surat mahasiswa dengan cara mengisi formulir pelayanan surat di kertas.

Pada administrasi pelayanan surat mahasiswa, terdapat beberapa masalah mengenai kekurangan dari sistem yang berjalan. Masalah dari sisi pelayanan yaitu banyaknya kertas yang harus di cetak untuk formulir pelayanan berbagai macam surat, petugas pelayanan juga masih harus memasukkan data pada formulir ke dalam surat yang di ajukan oleh mahasiswa secara manual dan tidak adanya kepastian waktu pengambilan surat, sehingga mahasiswa harus mengecek sendiri apakah surat telah selesai. Hal-hal tersebut dapat memperlambat pelayanan yang ada. Ditambah lagi karena keterbatasan waktu serta jarak yang harus ditempuh karena harus datang langsung ke kampus [6].

Selain mekanisme persuratan, pengarsipan data yang dilakukan secara manual juga memberi dampak buruk bagi petugas pelayanan, di antaranya adalah lambatnya pencarian informasi jika dibutuhkan, kemudian keberadaan surat atau dokumen lain yang sulit ditelusuri, serta penggunaan kertas yang tidak efisien [7]. Pelayanan administrasi ini juga merupakan faktor yang berpengaruh signifikan terhadap kepuasan mahasiswa pada pelayanan akademik [8]. Permasalahan ini membuktikan bahwa sistem yang sedang berjalan sekarang, perlu melakukan perubahan dari sistem pelayanan yang bersifat manual menjadi sistem pelayanan berbasis teknologi informasi melalui jaringan internet. Dengan adanya sistem administrasi pelayanan surat ini dapat membantu pengguna baik mahasiswa, maupun staf akademik untuk memberikan kemudahan akses layanan persuratan [9].

Pada penelitian sebelumnya, yang dilakukan oleh Sirhan Fikri, Wahyu Wiyani, dan Agung Suwandaru, mengenai pengaruh kualitas pelayanan terhadap kepuasan dan loyalitas mahasiswa adalah untuk mengetahui seberapa besar pengaruh variabel kualitas pelayanan dalam mempengaruhi kepuasan dan loyalitas mahasiswa. Hasil dari penelitian ini adalah kualitas pelayanan berpengaruh signifikan terhadap loyalitas [10].

Penelitian berikutnya yang berjudul sistem informasi e-office pendukung program paperless korespondensi perkantoran (Studi Kasus: Bagian Administrasi Akademik Akademi Komunitas Semen Indonesia Gresik), Totok Mulyono dan Kholid menghasilkan sistem informasi eoffice yang dapat memudahkan kinerja pegawai untuk mengurus administrasi khususnya dokumen persuratan dan korespondensi [11].

Selanjutnya penelitian yang dilakukan oleh Budi Rahman, Budi Susetyo, dan Dewi Primasari mengenai analisis kinerja pelayanan surat-menyurat berbasis web di PGRI Kabupaten Bogor bertujuan membangun sebuah sistem informasi berbasis web yang dapat membantu meningkatkan kinerja pelayanan surat menyurat [12]. Kurniawan, Dodik dalam penelitiannya menghasilkan sistem informasi pelayanan administrasi penduduk berbasis dekstop yang dapat memudahkan petugas IT desa dalam melakukan pelayanan administrasi penduduk yang lebih baik dan lebih transparan.

Penelitian yang dilakukan ini berdasarkan hasil pengamatan peneliti bahwa banyaknya permasalahan yang dihadapi oleh instansi pemerintahan desa dimana proses pelayanan surat menyurat dan pengolahan data penduduk yang masih menggunakan cara konvensional. Petugas juga masih harus mencatat secara manual data dari pemohon sehingga pada prosesnya akan membutuhkan waktu yang lebih untuk melakukan pelayanan [13].

\section{Metodologi Penelitian}

Metode yang digunakan pada penelitian ini metode waterfall dimana metode ini melakukan pendekatan yang sistematis dan berurutan pada pengembangan perangkat lunak, yang dimulai dengan tahapan analisis kebutuhan, tahapan perencanaan, tahapan pemodelan, tahapan konstruksi, serta tahapan akhir yaitu penyerahan sistem / perangkat lunak ke para pengguna [14].

Pada penelitian ini langkah-langkah yang dilakukan ialah requirements, analysis, design coding dan testing. Adapun penjelasannya sebagai berikut:

\section{1) Requirements}

Pada tahap ini yang dilakukan adalah pengumpulan data dan penetapan kebutuhan sistem yang akan dibangun. Pengumpulan data dilakukan dengan melakukan observasi, wawancara dan melakukan studi literatur. Observasi yang dilakukan yaitu dengan melakukan pengamatan langsung pada objek penelitian dalam hal ini Politeknik TEDC Bandung, yang berkaitan dengan proses pelayanan surat mahasiswa. Sedangkan wawancara yang dilakukan kepada staff akademik untuk menanyakan tentang informasi instansi tersebut dan menanyakan informasi proses pelayanan surat mahasiswa dan hal lain yang masih belum jelas pada saat pengumpulan data. 


\section{2) Analysis}

Pada tahap ini, yang dilakukan adalah menganalisis alur sistem administrasi pelayanan surat mahasiswa yang sedang berjalan di Politeknik TEDC Bandung, kemudian melakukan analisis data yang diperoleh sehingga mendapatkan hal-hal yang diperlukan untuk sistem yang akan dibangun.

\section{3) Design}

Pada tahap ini, yang dilakukan adalah menerjemahkan dari keperluan atau data yang telah dianalisis untuk menjadi sistem administrasi pelayanan surat mahasiswa pada Politeknik Tedc Bandung yang akan dibangun seperti merancang database dengan menggunakan MySQL dan merancang user interface atau tampilan sistem ke dalam bentuk yang mudah dimengerti oleh pengguna, baik tampilan dalam web ataupun mobile.

\section{4) Coding}

Pada tahap ini, yang dilakukan adalah menerjemahkan design, atau pemecahan masalah yang telah dirancang sebelumnya ke dalam bahasa pemrograman, bahasa pemrograman yang gunakan yaitu menggunakan bahasa pemrograman PHP dan Java (android).

\section{5) Testing}

Pada tahap terakhir, yang dilakukan yaitu pengujian dengan metode Black Box terhadap sistem administrasi pelayanan surat mahasiswa berbasis web dan mobile android.

\subsection{Analisis Sistem Berjalan}

Analisis sistem pelayanan surat mahasiswa yang sedang berjalan di Politeknik TEDC Bandung saat ini, seluruhnya masih dilakukan secara tatap muka dan belum ada suatu media pelayanan surat mahasiswa online yang memanfaatkan teknologi informasi untuk menunjang kebutuhan mahasiswa terhadap pelayanan yang diberikan oleh akademik.

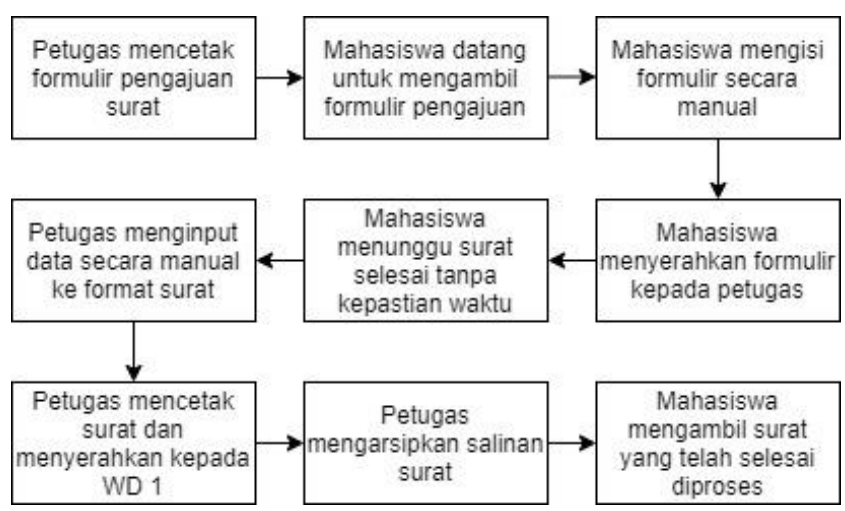

Gambar 1. Analisis Sistem Berjalan

Dalam hal ini, pelayanan surat mahasiswa dapat dikatakan masih dilakukan secara konvensional yaitu petugas pelayanan masih harus memasukkan data pada formulir ke dalam surat yang di ajukan oleh mahasiswa secara manual.

Hal-hal yang dilakukan dalam proses pelayanan surat mahasiswa antara lain:

1) Petugas Pelayanan:

- Petugas pelayanan mencetak berbagai macam formulir untuk pengajuan surat mahasiswa.

- Petugas pelayanan memasukkan data secara manual dari formulir pengajuan ke bentuk surat pengajuan.

- Petugas pelayanan mencetak surat.

- Petugas pelayanan menyerahkan surat kepada Wakil Direktur I untuk ditanda tangani.

- Petugas pelayanan mengarsipkan selembar surat pengajuan, untuk pengarsipan surat mahasiswa.

2) Mahasiswa:

- Mahasiswa datang ke bagian akademik kampus untuk membuat pengajuan surat.

- Mahasiswa mengambil formulir pengajuan surat dan mengisi formulir tersebut secara manual.

- Mahasiswa menyerahkan kembali formulir pengajuan surat kepada staf pelayanan.

- Mahasiswa menunggu surat selesai tanpa ketentuan waktu yang jelas.

- Mahasiswa mengambil surat tersebut, setelah surat selesai di proses.

Pada proses pelayanan surat mahasiswa tersebut, banyak memiliki keterbatasan tersendiri yang berakibat pada ketidak maksimalnya pelayanan mahasiswa. Lambatnya informasi yang di terima mahasiswa karena harus menunggu selesainya surat tanpa kejelasan yang pasti, sehingga membuat mahasiswa berulang kali mengecek pengajuan surat tersebut.

\subsection{Analisis Sistem yang dikembangkan}

Sistem yang akan di kembangkan terdiri dari dua aplikasi diantarnya aplikasi berbasis web, dapat digunakan oleh admin dan petugas pelayanan untuk mengelola data mahasiswa, serta mengelola surat yang diajukan oleh mahasiswa. Selain itu, aplikasi web juga dapat di akses oleh mahasiswa dengan batasan hak akses mahasiswa. Sistem yang dikembangkan juga lainnya adalah aplikasi berbasis mobile android, digunakan khusus untuk mahasiswa, agar dapat melakukan pengajuan surat dan menerima notification untuk informasi bahwa surat telah selesai diproses dan bisa langsung diambil.

Sistem ini dibuat untuk membantu dan diharapkan dapat mempercepat kinerja di bagian pelayanan akademik dalam pembuatan surat mahasiswa, serta dapat mempermudah mahasiswa dalam membuat pengajuan surat. Pada Gambar 2 adalah alur yang menggambarkan proses data dari aplikasi pelayanan surat mahasiswa yang dibuat. 


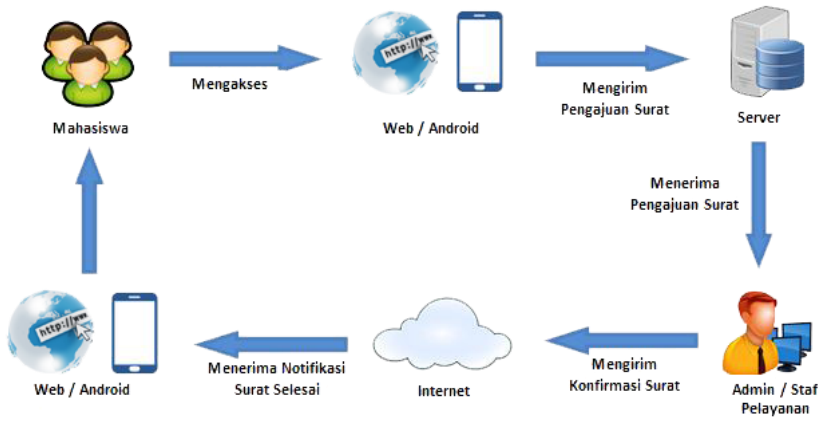

Gambar 2. Alur Proses Pelayanan Surat

Berdasarkan pada Gambar 2 dapat dideskripsikan bahwa:

- Mahasiswa yang telah terdaftar melakukan login dan masuk ke halaman mahasiswa.

- Mahasiswa memilih menu pengajuan surat yang ingin diajukan, kemudian mengisi formulir pengajuan surat berdasarkan surat yang ingin diajukan, baik di web maupun di android.

- Data surat yang telah di input oleh masing-masing actor akan tersimpan dalam basis data pada server.

- Petugas pelayanan akan melanjutkan prosedur pembuatan surat berdasarkan data yang telah ada pada basis data, seperti mengecek pada data lalu mencetak dalam bentuk lembar surat.

- Setelah surat selesai diproses, petugas pelayanan memberikan konfirmasi dengan mengubah status surat menjadi selesai diproses / dapat di ambil.

- Mahasiswa akan menerima notifikasi melalui smartphone android apabila surat telah selesai di proses, mahasiswa juga akan mendapat notifikasi jika login di halaman web.

- Data surat yang telah di cetak atau di proses, akan di tampilkan di data surat mahasiswa saat mahasiswa login ke halaman mahasiswa.

- Untuk di android, data surat mahasiswa dari database, akan di parsing dengan metode JSON dan di tampilkan ke dalam aplikasi di android, saat mahasiswa login ke halaman mahasiswa.

\subsection{Use Case Diagram}

Perancangan Sistem dalam penelitian ini menggunakan Unified Model Language (UML). UML merupakan pemodelan perancangan sistem informasi yang digunakan untuk mendefinisikan kebutuhan sistem, analisis, desain dan arsitektur berbasis Object Oriented Programming (OOP) [15].

Use case diagram digunakan untuk menjelaskan kegiatan yang dapat dilakukan oleh admin dan pengguna aplikasi. Sebuah use case hanya menjelaskan apa yang dilakukan oleh actor dan sistem. Adapun pada sistem pelayanan surat mahasiswa ini, use case diagram dapat dilihat pada Gambar 3.

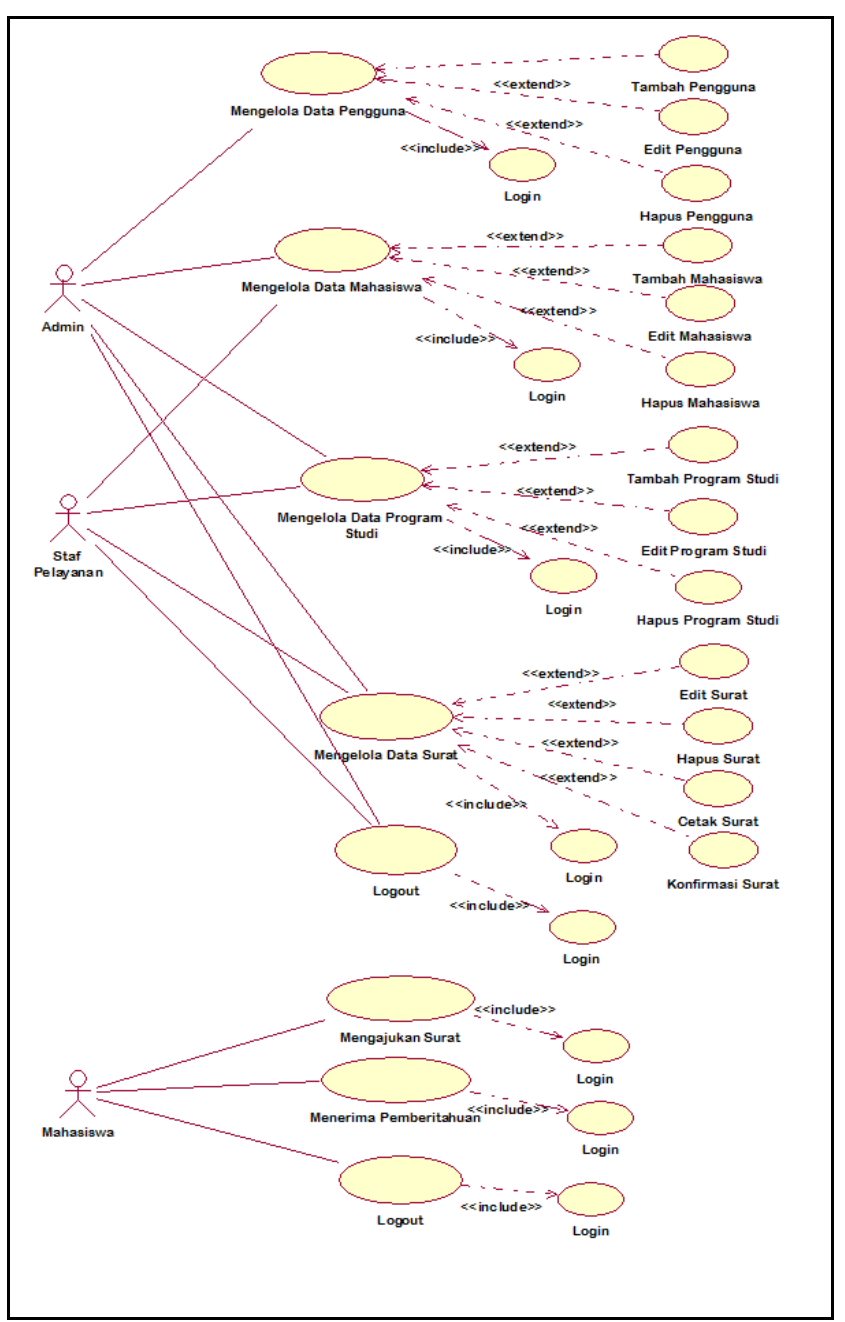

Gambar 3. Use Case Diagram

Berikut ini adalah deskripsi dari Gambar 3 mengenai use case diagram pada sistem administrasi pelayanan surat mahasiswa di Politeknik TEDC Bandung:

1) Use Case pada actor Admin:

- Login, digunakan untuk melakukan verifikasi admin sebelum masuk kedalam sistem.

- Mengelola data pengguna, digunakan untuk menambah, menghapus dan mengedit data pengguna beserta hak aksesnya.

- Mengelola data mahasiswa, digunakan untuk menambah, menghapus, dan mengedit data mahasiswa.

- Mengelola data program studi, digunakan untuk menambah, menghapus, dan mengedit data program studi.

- Mengelola data surat, digunakan untuk mengedit, menghapus, dan mencetak surat yang masuk, serta mengirim konfirmasi ke mahasiswa.

- Logout, digunakan admin untuk keluar dari sistem. 
2) Use Case pada actor petugas pelayanan:

- Login, digunakan untuk melakukan verifikasi data staf pelayanan sebelum masuk ke dalam sistem.

- Mengelola data mahasiswa, digunakan untuk menambah, menghapus, dan mengedit data mahasiswa.

- Mengelola data program studi, digunakan untuk menambah, menghapus, dan mengedit data program studi.

- Mengelola data surat, digunakan untuk mengedit, menghapus, dan mencetak surat yang masuk, serta mengirim konfirmasi ke mahasiswa.
- Logout, digunakan staf pelayanan untuk keluar dari sistem.

3) Use Case pada actor Mahasiswa

- Login, digunakan untuk melakukan verifikasi data mahasiswa sebelum masuk ke dalam sistem.

- Mengajukan Surat, digunakan untuk membuat pengajuan surat.

- Menerima Konfirmasi, digunakan untuk melihat pemberitahuan bahwa surat telah selesai diproses.

- Logout, digunakan mahasiswa untuk keluar dari sistem.

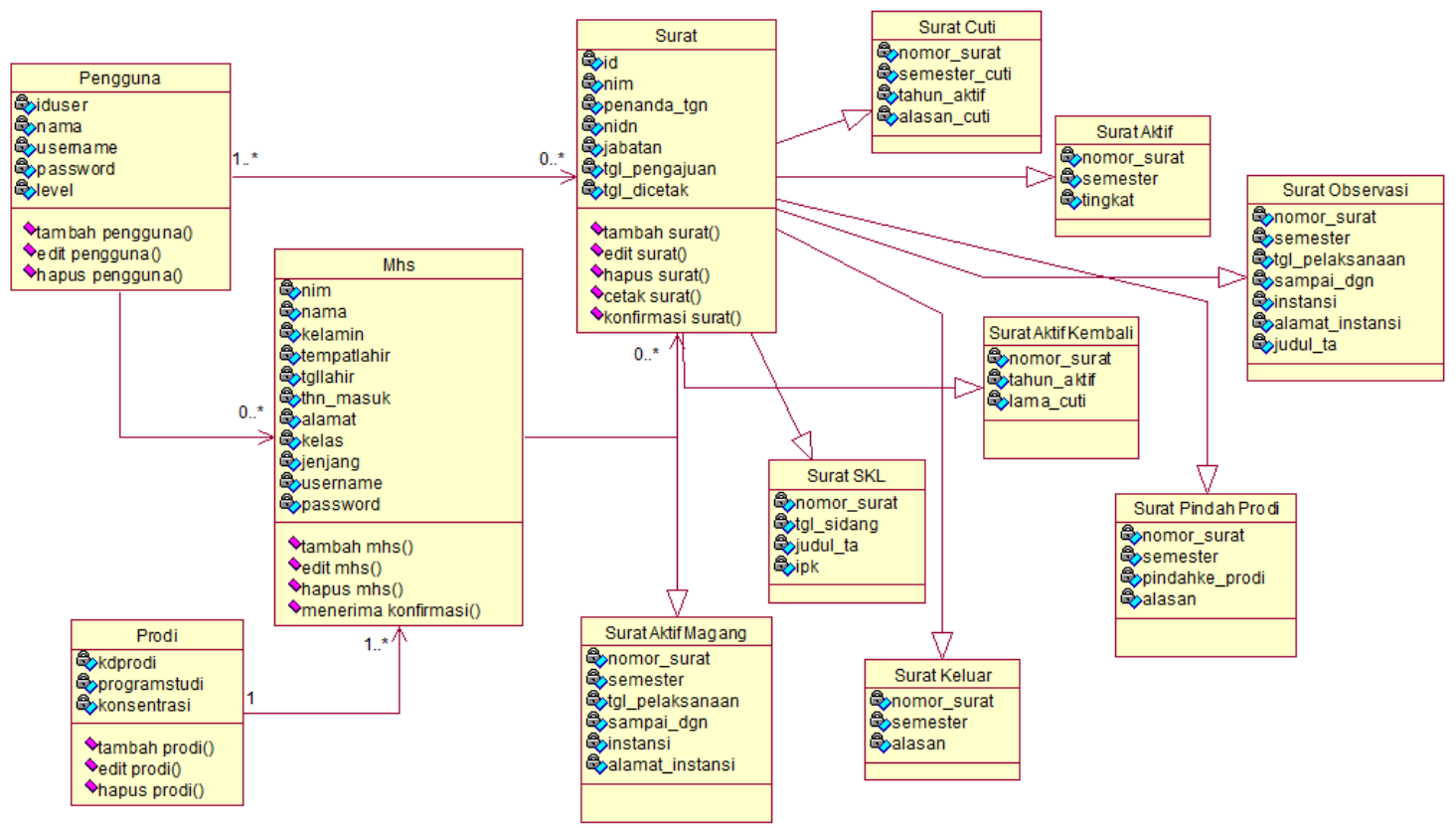

Gambar 4. Class Diagram
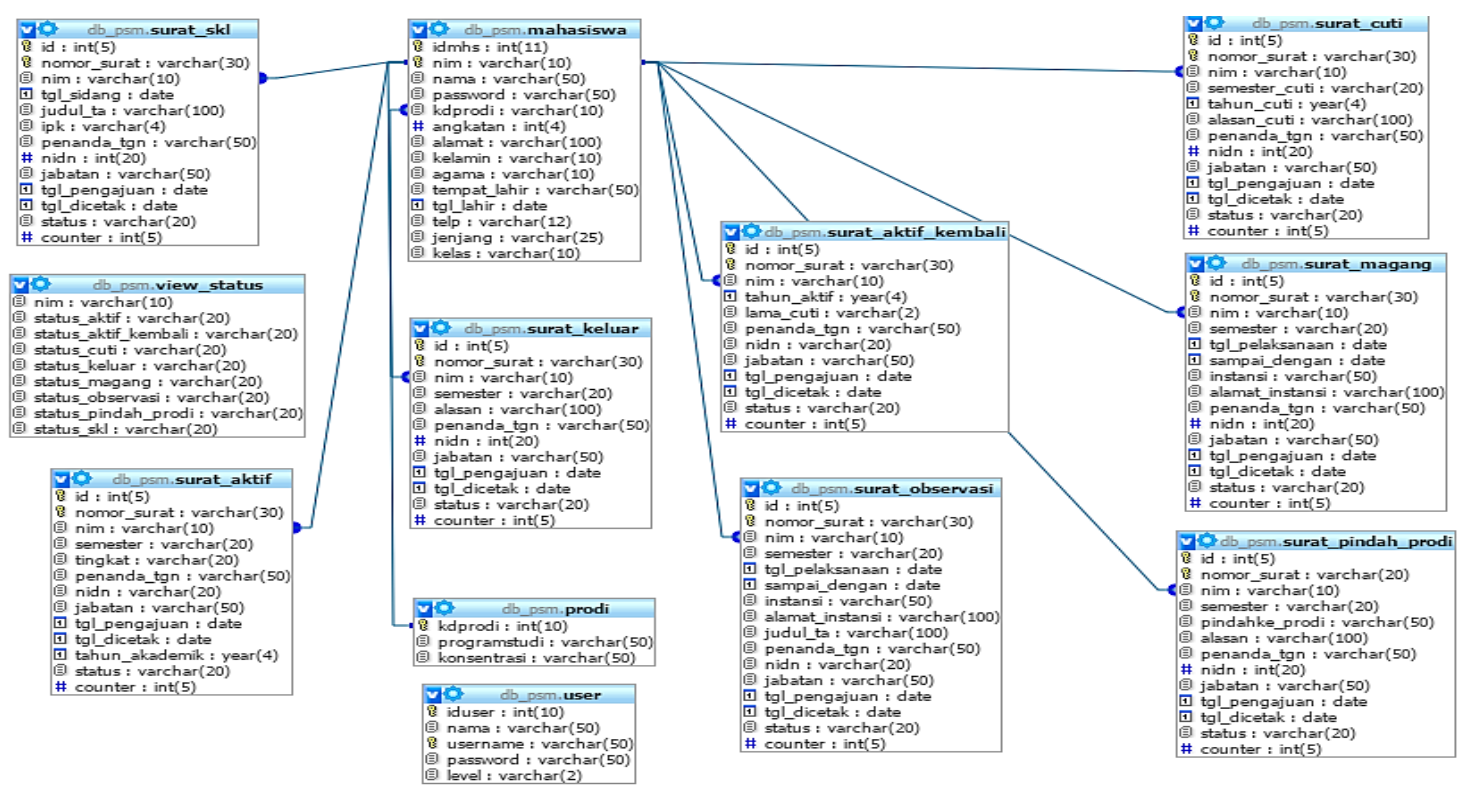

Gambar 5. Rancangan Basis Data 


\subsection{Class Diagram}

Class diagram menggambarkan struktur dan deskripsi class beserta hubungan satu sama lain seperti Asosiasi, Generalisasi dan lain sebagainya. Dalam gambar 4 digambarkan hubungan antar class untuk admin yang terjadi pada sistem yang akan dibangun.

\subsection{Perancangan Basis Data}

Perancangan basis data ini termasuk bagian yang sangat penting dalam pembuatan sistem administrasi pelayanan surat mahasiswa di Politeknik TEDC Bandung ini. Basis data ini di rancang sebagai tempat penyimpanan data - data yang terhubung ke dalam aplikasi. Basis data yang akan digunakan dalam aplikasi ini adalah basis data MySql. Rancangan basis data digambarkan pada Gambar 5.

\subsection{Perancangan Antar Muka Pengguna}

Perancangan antar muka dari sistem administrasi pelayanan surat mahasiswa di Politeknik TEDC Bandung ini dibagi menjadi dua, yaitu tampilan pada website dan tampilan pada mobile android.

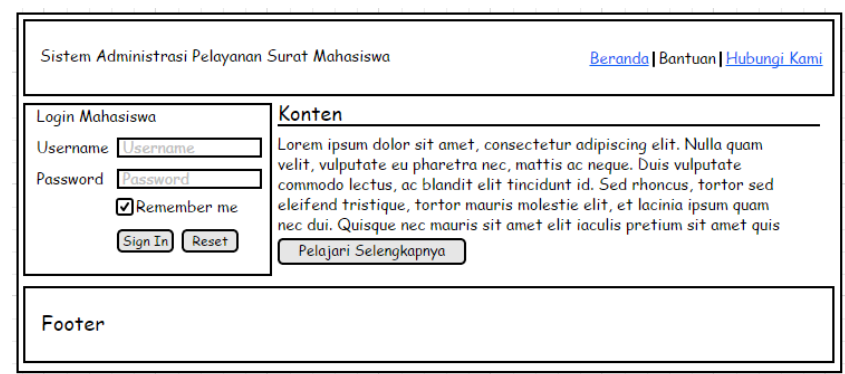

Gambar 6. Rancangan Login Mahasiswa

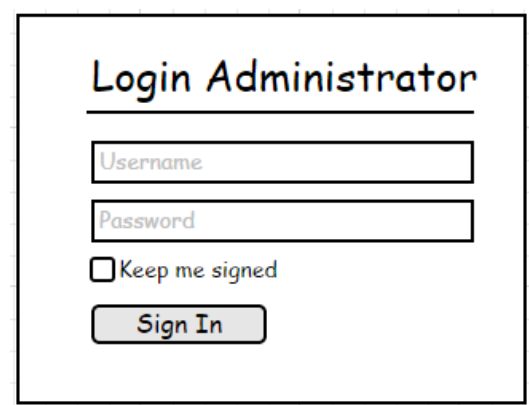

Gambar 7. Rancangan Login Admin

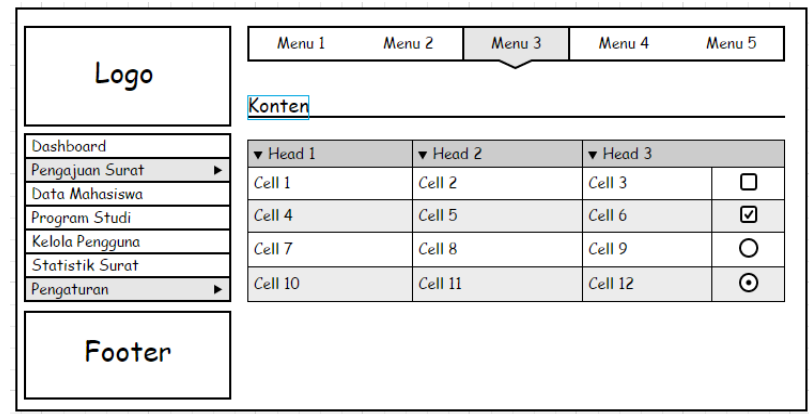

Gambar 8. Rancangan Halaman Admin
Perancangan tampilan pada website terdiri dari beberapa halaman, yaitu halaman login mahasiswa, halaman login administrator, halaman mahasiswa, halaman admin, dan halaman staf pelayanan seperti diperlihatkan pada Gambar 6.

Selain mahasiswa, admin dan staf juga diharuskan untuk login terlebih dahulu. Hal ini dimaksudkan untuk memverifikasi pengguna dan hak aksesnya, yang akan menggunakan sistem. Rancangan halaman login dapat dilihat pada Gambar 7. Setelah admin melakukan login ke dalam sistem, selanjutnya admin akan memasuki halaman utama dari sistem. Rancangan halaman menu utama ini dapat dilihat pada Gambar 8.

\section{Hasil dan Pembahasan}

Penelitian ini menghasilkan sistem administrasi pelayanan surat mahasiswa yang dapat dimanfaatkan oleh mahasiswa serta petugas pelayanan surat. Pada Gambar 9 menjelaskan tentang halaman login yang digunakan oleh petugas pelayanan administrasi untuk menggunakan sistem ini. Proses pendaftaran petugas pelayanan dapat dilakukan oleh admin.

Menu yang terdapat pada sistem administrasi ini antara lain dashboard, pengajuan surat, data mahasiswa, program studi, Kelola pengguna, statistik surat serta pengaturan. Kelebihan dari sistem ini adalah adanya notifikasi kepada petugas pelayanan saat ada pengajuan surat, serta mahasiswa dapat mengecek langsung, proses dari pengajuan surat. Mahasiswa juga akan mendapatkan notifikasi, ketika surat telah selesai dan dapat diambil.

Berikut merupakan hasil dari perancangan yang sebelumnya sudah dilakukan pada tahap perancangan, diantaranya adalah Halaman Login yang menampilkan inputan username dan password digunakan oleh admin, terliat pada Gambar 9. Halaman menu utama seperti pada gambar 10 adalah halaman yang akan muncul setelah admin melakukan login.

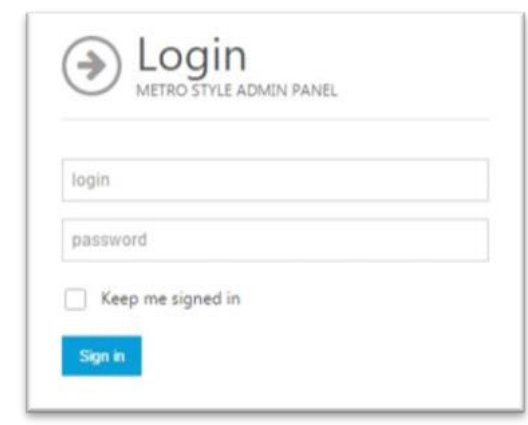

Gambar 9. Tampilan Login

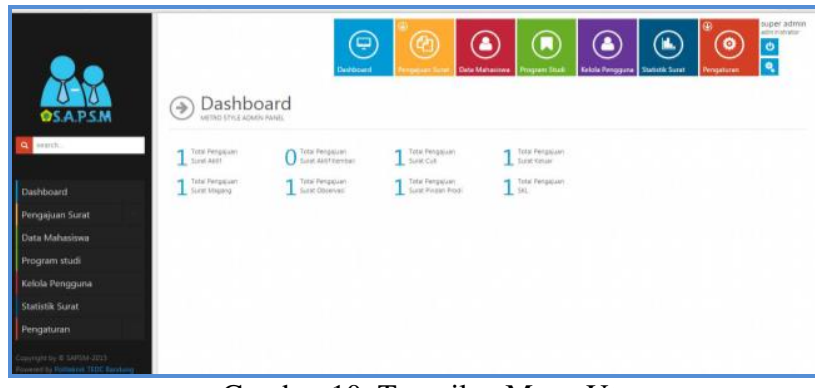

Gambar 10. Tampilan Menu Utama 
Halaman login adalah halaman pertama yang tampil pada saat mahasiswa mengakses website, pada Gambar 11 . Untuk tampilan halaman login pada Gambar 12 merupakan tampilan ketika mengakses aplikasi menggunakan mobile android. Pada Gambar 13 merupakan tampilan merupakan tampilan di menu utama mahasiswa.

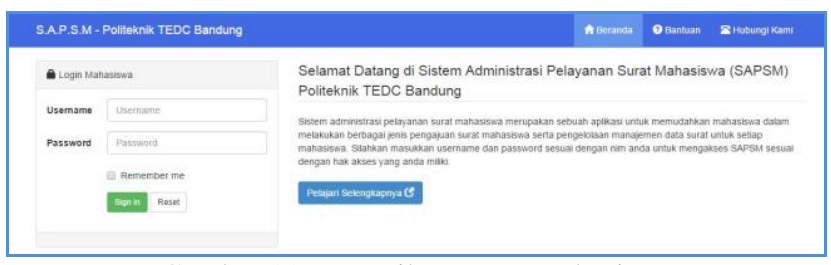

Gambar 11. Tampilan Login Mahasiswa

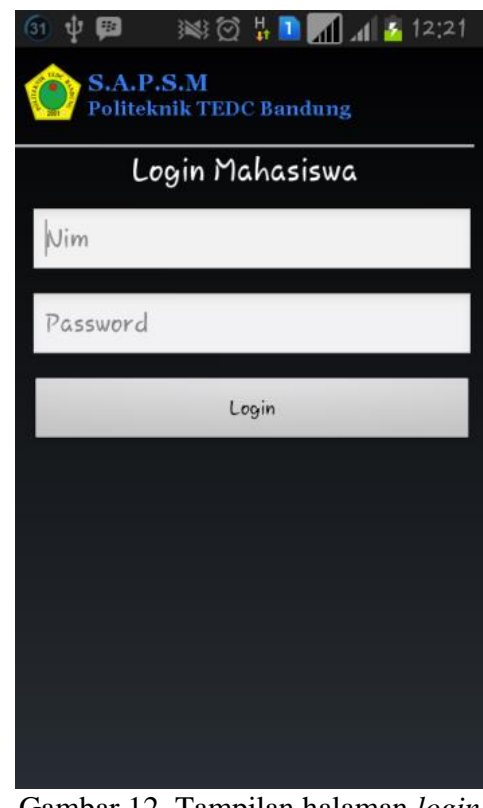

Gambar 12. Tampilan halaman login

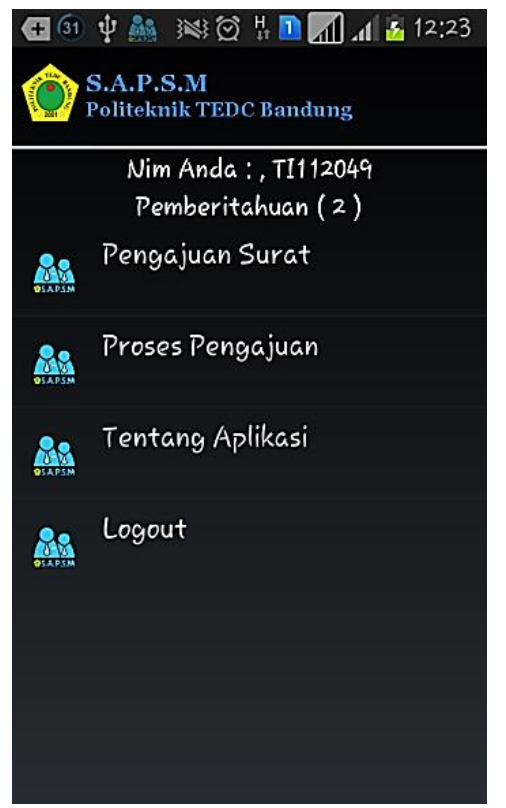

Gambar 13. Tampilan halaman mahasiswa
Sistem administrasi pelayanan surat mahasiswa berbasis web dan mobile android memiliki pengguna admin (petugas pelayanan) dan mahasiswa. Admin memiliki hak akses CRUD (Create Read Update Delete) data pengajuan surat, data mahasiswa, data program studi, dan Kelola pengguna. Pada Tabel 1 memperlihatkan hasil pengujian menggunakan black-box. Halaman yang diuji menggunakan metode black-box adalah halaman dashboard, pengajuan surat, data mahasiswa, program studi, kelola pengguna, statistik surat serta pengaturan. Hasil pengujian fungsionalitas Sistem Administrasi Pelayanan Surat Mahasiswa yaitu setiap halaman berfungsi dengan baik.

Berdasarkan hasil survey yang dilakukan terhadap 20 responden bahwa sistem ini mampu memudahkan mahasiswa dalam hal pengajuan surat. Tabel 2 menjelaskan hasil survey terhadap pengajuan surat mahasiswa. Dari hasil pengujian, terbukti bahwa sistem mampu melakukan pengelolaan pengajuan surat mahasiswa. Hasil rata-rata dari lima pertanyaan diatas didapatkan hasil 82,8 \%. Hasil perhitungan dilakukan dengan cara menjumlahkan semua hasil dari masing-masing pertanyaan kemudian dibagi dengan angka lima.

\begin{tabular}{lll}
\multicolumn{3}{c}{ Tabel 1. Pengujian Black-box } \\
\hline \multicolumn{1}{c}{ Halaman } & \multicolumn{1}{c}{ Kondisi } & Hasil \\
\hline Dashboard & $\begin{array}{l}\text { Melihat dashboard } \\
\text { Pengajuan Surat } \\
\text { Melakukan lihat, } \\
\text { tambah, edit, hapus } \\
\text { data surat. }\end{array}$ & $\begin{array}{l}\text { Berhasil } \\
\text { Berhasil }\end{array}$ \\
& $\begin{array}{l}\text { Melakukan lihat, } \\
\text { tambah, edit, hapus } \\
\text { data mahasiswa. }\end{array}$ & Berhasil \\
Program Studi & $\begin{array}{l}\text { Melakukan lihat, } \\
\text { tambah, edit, hapus } \\
\text { data program studi. }\end{array}$ & Berhasil \\
Kelola Pengguna & $\begin{array}{l}\text { Melakukan lihat, } \\
\text { tambah, edit, hapus }\end{array}$ & Berhasil \\
data pengguna. & \\
Statistik Surat & $\begin{array}{l}\text { Melihat statistic surat } \\
\text { Pengaturan }\end{array}$ & Mengubah pengaturan \\
\hline
\end{tabular}

Tabel 2. Hasil Survey Pengguna

\begin{tabular}{clc}
\hline No & \multicolumn{1}{c}{ Pertanyaan } & $\begin{array}{c}\text { Rata-rata } \\
\text { Persentase }\end{array}$ \\
\hline 1 & $\begin{array}{l}\text { Sistem administrasi pelayanan surat } \\
\text { mahasiswa dapat dengan mudah digunakan } \\
\text { oleh pengguna. }\end{array}$ & $85 \%$ \\
2 & $\begin{array}{l}\text { Sistem administrasi pelayanan surat } \\
\text { mahasiswa sesuai dengan kebutuhan } \\
\text { pengguna. }\end{array}$ & $86 \%$ \\
3 & $\begin{array}{l}\text { Sistem administrasi pelayanan surat } \\
\text { mahasiswa dapat membantu kinerja petugas } \\
\text { pelayanan surat. }\end{array}$ & $83 \%$ \\
4 & $\begin{array}{l}\text { Sistem administrasi pelayanan surat } \\
\text { mahasiswa dapat membantu pengolahan } \\
\text { data pada pelayanan surat mahasiswa. } \\
\text { Sistem administrasi pelayanan surat } \\
\text { mahasiswa dapat mempercepat kinerja } \\
\text { petugas pelayanan. }\end{array}$ & $80 \%$ \\
\hline
\end{tabular}




\section{Kesimpulan}

Berdasarkan hasil pengujian black-box, sistem dapat berfungsi dengan baik. Berdasarkan pengolahan data dari responden mengenai hasil pengujian sistem, 82,8\% responden setuju bahwa sistem mampu melakukan pengelolaan pengajuan surat mahasiswa, sehingga dapat diambil kesimpulan bahwa, sistem administrasi pelayanan surat mahasiswa ini dapat mempermudah pekerjaan petugas pelayanan dalam mengelola surat mahasiswa.

\section{Daftar Pustaka}

[1] N. R. R. Julian Chandra Wibawa, "Pembangunan Sistem Informasi Pengelolaan Surat Pada Program Studi Sistem Informasi Unikom," JAMIKA, vol. 8, no. 1, 2018.

[2] R. H. Widodo, S. Rahman, and H. Arfandy, "Kharisma Makassar Dengan Menggunakan," vol. 5, no. 2, pp. 51-61, 2018.

[3] M. Rizal and J. Puja, Persuratan Akademik Berbasis Web Uin Walisongo Semarang. 2017.

[4] P. Sukana, "Sistem Informasi Kearsipan Akademik Pada Fakultas Teknik Universitas Pgri Yogyakarta," vol. 2015, no. June, p. 50061, 2016.

[5] D. Kurniadi and A. Mulyani, "Implementasi Pengembangan Student Information Terminal (S-IT) Untuk Pelayanan Akademik Mahasiswa," J. Algoritm., vol. 13, no. 2, pp. 437442, 2017, doi: 10.33364/algoritma/v.13-2.437.

[6] D. A. Noery, "Digital self service: sistem pengajuan persuratan bagi mahasiswa uin ar-raniry banda aceh menggunakan php mysql," 2019.

[7] H. Setyawan, "Strategi Organizational Development Melalui Aplikasi Persuratan dan Kearsipan Elektronik My Office di Universitas Negeri Yogyakarta," Dipl. J. Kearsipan Terap., vol. 2, no. 1, p. 34, 2018, doi: 10.22146/diplomatika.39527.
[8] D. Marlius, "Pengaruh Dimensi Kualitas Pelayanan Website Akademik Terhadap Kepuasan Mahasiswa Pada Stie 'Kbp,"” J. Ipteks Terap., vol. 12, no. 2, p. 116, 2018, doi: 10.22216/jit.2018.v12i2.633.

[9] A. M. Latief, M. Hasbi, and Syawaluddin, "Aplikasi Layanan Akademik Mahasiswa Berbasis Software," Irfani J. Islam. Educ., vol. 15, no. 2, pp. 36-52, 2019, [Online]. Available: http://journal.iaingorontalo.ac.id/index.php/ir/article/view/11 68.

[10] S. Fikri, W. Wiyani, and A. Suwandaru, "Pengaruh Kualitas Pelayanan Terhadap Kepuasan dan Loyalitas Mahasiswa (Studi pada Mahasiswa Strata I Fakultas Ilmu Sosial dan Ilmu PolitikUniversitas Merdeka Malang)," J. Bisnis dan Manaj., vol. 3, no. 1, p. 122, 2016.

[11] T. Mulyono, "Sistem Informasi E-Office Pendukung Program Paperless Korespondensi Perkantoran ( Studi Kasus : Bagian Administrasi Akademik Akademi Komunitas Semen Indonesia Gresik )," Tecnoscienza, vol. 2, no. 2, pp. 108-122, 2018.

[12] B. Rahman, B. Susetyo, and D. Primasari, “Analisis Kinerja Pelayanan Surat-Menyurat Berbasis Web Di Pgri Kabupaten Bogor," IKRA-ITH Inform. J. Komput. dan Inform., vol. 3, no. 1, pp. 1-11, 2019, [Online]. Available: http://journals.upi-yai.ac.id/index.php/ikraithinformatika/article/view/282.

[13] D. Kurniawan, "Rancang Bangun Sistem Informasi Pelayanan Administrasi Penduduk Pada Kantor Desa Kasreman Kecamatan Kandangan Kabupaten Kediri," Ekon. Akunt., vol. 01, no. 08, pp. 1-13, 2016.

[14] R. S. Presman, Rekayasa Perangkat Lunak (Pendekatan Praktisi). 7th ed. Jogjakarta: Andi Offset, 2012.

[15] R. A. S. and M. Shalahuddin, "Modul Pembelajaran Rekayasa Perangkat Lunak (Terstruktur dan Berorientasi Obyek)," vol. 53, no. 1, 2013. 